\title{
DESCRIPTIONS PLUS TYPES VS. DESCRIPTIONS
} ALONE. ${ }^{1}$

\author{
By Clarence E. Mickel, \\ University of Minnesota.
}

In a recent article in Psyche [36(3) :228-231, September, 1929] entitled "Down with the Type-Cult," Professor Embrik Strand of the University of Riga, Latvia, condemns the practice of designating type specimens when a new species is described, charges that their use is contrary to the International Rules of Nomenclature, and urges the principle that the description should be the final and only authority in deciding disputed points regarding the identity of a species.

The principal arguments advanced by Professor Strand in his opposition to the use of types may be summarized as follows: (1) that the early authors such as Linné, Fabricius and others did not designate or use types, therefore we should not; (2) that the establishment of species on the basis of types is opposed to the rules of nomenclature; (3) that even if one asserts that the types have been used only in order to verify and better the descriptions, it is likewise an abuse, if it leads to conclusions that are quite contradictory to the descriptions; (4) that type specimens are the fashion because certain taxonomists by their use are able to dominate taxonomy, and therefore have a personal interest in maintaining the practice; (5) that in most cases the types are not accessible to the worker, that on this account it will soon be impossible to write a monograph if the examination of the types is to be considered a necessary prerequisite, and that therefore the practice of designating

\footnotetext{
${ }^{1}$ Published with the approval of the Director as Paper No. 215, of the Miscellaneous Series of the Minnesota Agricultural Experiment Station.
} 
and using types should be abolished; (6) that the entomological public is obviously apt to place more confidence in the new "examiner" of the type than in the original describer, and that to protect the latter and do him justice the practice of designating and using types should no longer be tolerated; (7) that when a specialist or reviser secures a second party to compare his specimens with the type, swindles are often perpetrated on the entomological community, and therefore the practice of using types should be dispensed with; and finally (8) that the description is quite an absolutely constant, invariable thing which is accessible to the whole world, and is therefore everything, and in case of a disputed point with regard to the identity of a species the description should be the final and only standard or authority.

It will be advantageous to consider these charges and arguments one by one and see how much basis in fact there is for maintaining them.

(1). The first point is that since early entomological workers did not use types, we should not; that since our forefathers did not do so-and-so, we should not; a sort of ancestor worship. If the work of the older authors be examined it will be found that they did not limit species as strictly as we do today; they did not realize the value of geographical, ecological and other precise data in taxonomic work, and consequently stated what data was available to them in exceedingly general terms. They could not foresee that the specimens of the species which they described would be of great value to future generations, and therefore paid little attention to them. Like certain workers of today they were so absorbed in writing descriptions of new species that this activity seemed to them to be the ultimate aim of taxonomy, and they therefore had no time for taking proper care of the specimens on which their work was based. Neither did they have any conception of the enormous number of species of insects that would eventually be found inhabiting the earth. If there were only ten, or a hundred, or a thousand, or even ten thousand species of insects known for the world the necessity for type speci- 
mens might not seem very obvious; but when the number of species rises to hundreds of thousands and possibly millions, then the need for some standard of reference for each species becomes very plain. So the older workers, who did not realize the enormous number of species of insects with which taxonomy would have to deal, had not come to feel the need of types, and to argue that since the older workers did not designate type specimens, we should not do so today, is to argue that the taxonomy of a hundred, or one hundred and fifty years ago is good enough for us, that progress and advancement in technique and analysis is undesirable in the field of taxonomic research. No taxonomist who is seriously interested in the improvement and advancement of taxonomic work would ever be tempted to adopt such a principle.

(2). The establishment of species on the basis of types is opposed to the rules of nomenclature. First it should be pointed out that the rules of nomenclature are not concerned with the establishment of species, but only with the names of species, subspecies, genera and other categories in use in the field of zoology. If by this statement Professor Strand means an attempt to establish a specific name on the basis of a museum specimen only, then he is quite correct and is supported in his contention by Opinion one, of the International Commission on Zoological Nomenclature, which states that in no case is the word "indication" to be construed as including museum specimens. If, however, he means that in an attempt to decide the identity of a species with a valid specific name, the use of, or designation of, a type specimen to solve the problem, is opposed to the International Rules, then he most certainly is incorrect, since the International Commission has ruled on that point in Opinion seventy-eight regarding the validity and identity of the names of two ticks. The validity of the names was decided on the basis of the first properly published description or indication, while the identity of each was decided on the basis of type specimens, which in both cases were designated some time after the first publication of the names. 
(3). If the conclusion reached by using a type specimen to supplement a description is contradictory to the latter, then it is an abuse. To show the impossibility of using any such principle as a criterion as to whether the use of types is scientific or not, it is only necessary to call attention to the innumerable cases in entomological literature where a description of a new species has been drawn up based on a series of two or more specimens. Such a description is a composite one, including characters seen by the author in all of the specimens before him. In many such cases we know now, or at least the evidence available leads us to believe, that this series of specimens consists of more than one species. Therefore, the description includes characters of all the species represented in the series of specimens which the author had before him when he wrote the description. For the sake of simplicity we will suppose that two species were represented in such a series of specimens. If a single specimen from the original series of specimens is designated as the type, then the species which it represents will have some characters which are contradictory to the description, because the latter is composite. If a specimen of the second species represented in the original series is designated as the type the result will be the same; it will be contradictory to the description. Then one is at an impassé, if this principle is to be adopted; the description applies to neither of the two species, since whichever one is selected brings results contradictory to the description, and the only other recourse is to place the description in that zoological graveyard "species incertæ sedis," where it will remain forever. If the description is everything, and nothing but that is used, the result is the same, since no object in nature is to be found but what is contradictory to the description to some degree, and the name, therefore, finds its way into the list of "species incertæ sedis." The adoption of this principle then, i. e., that if a type is used to supplement a description, and the conclusion reached thereby is contradictory to the description, then the use of the type is an abuse, would only lead to more confusion, additional names for which we could find no objects in nature, and more inaccuracies in taxonomic work. 
(4). It is implied that type specimens have come to be so widely used, not because they have added an element of certainty and exactness to taxonomic work, but because certain taxonomists by their use are able to dominate taxonomy, and therefore have a personal interest in maintaining a type system, that they secure for themselves either power or personal aggrandizement by the perpetuation and strengthening of such a system. Granting for the moment that such a motive were possible, would the situation be any worse than that which now exists and which allows an individual to acquire eminence and renown as a taxonomist, although he contribute nothing more to taxonomy than an endless number of descriptions of new species, to which his name must be attached. The idea that the describing of species may be a major objective in taxonomic work is seriously questioned by many present-day entomologists. Just what personal power and aggrandizement can be secured by an individual by basing his taxonomic work on type specimens is not made clear, and the charge that the practice of designating types for species is maintained by those who personally profit from the system, sounds strikingly similar to the charge usually made by the opposition, who refuse to see any good in any new idea, and who in order to encourage prejudice against it, accuse the proponents of promoting their own personal interests. As a matter of fact, type specimens were first used, and their use continues and is being perfected, because they have contributed an element of standardization to taxonomic work. A type specimen constitutes a standard by which other individuals of the same species may be measured and compared, and when so used it contributes accuracy and exactness to a field where doubt and confusion have been prevalent. When a nation desires some standard for a unit of weight, measure, etc., does it write up a lengthy description of the particular unit and declare that this description will be the only and final authority to determine what the unit actually is? It does not. Some sort of a material standard representing the particular unit is set up and is very carefully kept and preserved. When questions of doubt arise as to the exact characteristics of 
the unit, the standard is the ultimate and only source of comparison by which any particular characteristic of the unit may be determined.

(5). Kleine's (1928) complaint is cited to the effect that the types in most cases are not accessible to the worker and shortly it will be quite impossible to write a monograph if an examination of the types is to be considered a necessary prerequisite for such work. Under present conditions, with types scattered in various places, there can be little question but that the amount of work and expense necessary to produce a monograph of any group of organisms would be greatly reduced if the examination of type specimens could be dispensed with, and any scientific worker is certainly at liberty to write a monograph based on nothing more than the descriptions of the species involved. But the author of such a monograph must remember that the scientific world will judge his contribution by the accuracy and exactness which he has been able to achieve by his method of treatment. The scientific world has learned from sorrowful experience that monographic works based on nothing but published descriptions are so inaccurate and untrustworthy as to be practically valueless, and while monographs prepared according to that method may still be produced, they are not very likely to receive serious consideration. The very fact that taxonomists have come to realize that scientifically sound and accurate work cannot be produced when based solely on descriptions, is the motivating force that has driven them to use a type specimen as a standard when some disputed point is to be decided. The use of type specimens has enabled taxonomists to achieve results of greater scientific value than the use of descriptions alone, and as long as types continue to contribute such a quality to taxonomic work, just so long will they be used, regardless of additional work or expense.

(6). Another objection to the use of types raised by Professor Strand is as follows: "That the entomological public is obviously apt to place more confidence in the new examiner of the type, than in the original describer. Who 
guarantees that the new examiner of the type is abler than the original describer in this respect? I think that it has often happened that the reviser has degraded a number of species into synonyms because he did not see the distinctive marks which the original describer stated, and which in reality are present." The truth is that the entomological public has no more confidence in the reviser, or new examiner of the type, than it has in the original describer. The work of both must stand or fall on its merits. As a matter of fact the original describer is better protected against injustices if he designates a holotype, than he is if he refuses to acknowledge the usefulness of types and clings to the theory that the description is everything. A description may be so poor that it is indistinguishable from that of several related species and if the description was everything the species would then be relegated to synonymy; but if a holotype has been designated, a standard can be examined and the status of the disputed species determined in relation to other species of its group. For every species that has been relegated to synonymy unjustly due to an examination of a type, three or four can be cited which have been elevated from synonymy to validity due to the fact that a type specimen was available for examination, and three or four more could be cited which are probably valid species, but which have been placed in synonymy because they are indistinguishable from previously described species on the basis of the description, and either no type is available, or if available, has not been examined. The best guarantee which a taxonomist can secure against injustices in the estimation of his work is a properly designated holotype for every species described, said holotype deposited in an institution where all may see.

(7). The comparison of specimens with the type by persons other than the reviser or specialist is resorted to relatively few times in entomological taxonomic work. That is, comparing the number of types actually examined by the reviser, with the number examined by proxy, the latter will be found to be relatively small. Judging from my own experience, the safeguards set up by the reviser to prevent 
the second party from arriving at an erroneous conclusion when comparing certain specimens with the type, are ample to prevent errors in most cases. Such precautions also testify to the good faith of the reviser and indicate that he is seeking for the truth regardless of what it may be. If taxonomists as a class are so intellectually dishonest as to swindle the entomological public in this way, as Professor Strand claims, how much easier it would be to perpetrate such swindles if the description were everything. It happens rather often that the descriptions of two species are indistinguishable when compared word for word. In such a case the reviser would need to go no further; his report would be that here are two descriptions exactly alike and therefore one of them must be relegated to synonymy. If the descriptions were everything no one could challenge his conclusion, since there would be no source of evidence with which to support such a challenge. Species have been relegated to synonymy by this method many times in the past, with the result that when the types were finally located and authenticated it was found that the description referred to a good and valid species. Descriptions or types, either one, will not prevent intellectually dishonest persons from perpetrating swindles, nor will the use of either one tempt an honest man to use dishonest methods in his research. If Professor Strand knows of concrete examples of such swindles, as he claims, it is his duty to bring them to the attention of entomological taxonomists, together with the facts and evidence to prove that they are swindles. To point out concrete examples and expose them as swindles will do more to eliminate dishonest work from the field of entomological taxonomy, than assailing a method of technique and mode of thought which has improved the quality of taxonomic work.

(8). And finally it is contended that the description is quite an absolutely constant, invariable thing which is accessible to the whole world, while the question is asked: "Who guarantees that the animal designated as the 'type' really is the type"? The implication in the question is, that taxonomists as a group, in the field of entomology, at 
least, are so dishonest and unreliable that type specimens in general cannot be relied upon to be what they claim to be, i. e., the original specimens from which descriptions or figures have been drawn, and in many cases designated as type by the author himself. If this implication of dishonesty and unreliability were true, who could guarantee that any published description was applicable to any organism existing in nature? If a worker is dishonest enough to manipulate types or type labels, he is dishonest enough to write descriptions of species based on nothing more than fancies of his imagination, with no counterpart in nature whatever. To be dishonest with respect to scientific descriptions or type specimens is like cheating at solitaire-one is only cheating himself. It is true that rogues may be found in every field of human activity, but they are usually comparatively rare in scientific professions. With respect to honesty and reliability, I believe that taxonomists as a group will compare favorably with any other group of scientists, or with other selected professional groups, and the implication that type specimens in general are unreliable, due to the dishonesty of taxonomic workers, seems to me to be entirely unjustifiable.

The theory that the description is everything is one that is not universally tenable. Article twenty-five of the International Rules of Nomenclature states: "The valid name of a genus or species can be only that name under which it was first designated on the condition (a) that this name was published and accompanied by an indication, or a defition, or a description." Opinion one of the International Commission states: "The word 'indication' in Article twenty-five-a is to be construed as follows: with regard to specific names, an 'indication' is (1) a bibliographic reference, or (2) a published figure (illustration), or (3) a definite citation of an earlier name for which a new name is proposed." In the case of two of these there is no description which can be everything. A bibliographic reference is a substitute for a description in validating a name. A published figure is either a substitute for a description, if the latter is lacking, or it is a supplement to the descrip- 
tion in case the latter is present. If the description is everything and objection is made to the type because it is a supplement to the description and therefore erroneous conclusions may be drawn from it, then a published figure is in the same class as the type. It is a supplement to the description and conclusions drawn from it may be contradictory to the description. If the principle "the description is everything," were rigidly construed, type specimens, published figures, museum specimens, or any description subsequent to the original one could not be used in the preparation of a monograph. How far would taxonomy progress if such a principle were adhered to? We would then have a mass of innumerable dogmas (descriptions) of which every word must be literally believed as true, and which would be looked upon as the final and only source of information regarding natural science. Such a condition actually existed in science for hundreds of years. From 200 A. D. to 1543 A. D. the written words of Galen describing the anatomy of the human body were looked upon as the final and only authority in this field. Galen's descriptions were everything. If discrepancies were found between Galen's descriptions and a dissected human cadaver, the descriptions were right, the cadaver wrong. During the period that this type of thought prevailed the spirit of scientific research was absent in all fields of knowledge, and anatomy as a science was stagnant. It was only when Vesalius overthrew authority and resorted to the dissection of the human body itself that anatomy began to progress as a science. Since Vesalius' time descriptions have been a necessary and useful method of recording scientific knowledge, but they have not been the final and only authority in anatomy or in any of the other sciences. In taxonomy individual specimens of the various species of animals and plants are our only source of information, and to outlaw such specimens, or even one selected specimen, designated as the type or standard, and to substitute therefore a written description is to substitute dogma for science, to substitute authority for research, a folly of the worst sort. 


\section{Suggestions Regarding the Use of Types}

Two practices now exist in the preservation and use of type specimens which make the work of the taxonomist who attempts any sort of a monographic revision much too difficult and expensive. Inasmuch as careful, accurate, analytical, monographic work is more needed in entomological taxonomy today than ever before, the modification of these practices in such a way as to remove the difficulties would have the effect of encouraging that type of work. These two practices are: (1) the policy of never loaning types from public museums under any circumstances; and (2) the practice of individual taxonomists in retaining holotypes in their private collections.

When any taxonomist undertakes the study of any limited group of insects, he usually finds that the holotypes are scattered over the earth among various institutions and individuals. In order to examine these holotypes it is necessary under present conditions to expend large amounts of money and time traveling to and from all of these places in order to accomplish the work. It frequently happens that the individual has neither the funds nor the time at his disposal to undertake the study of the types, and the result is that he produces either a distinctly inferior piece of work than that of which he is capable, or he produces nothing at all. The types are indispensable and should be religiously preserved, but we surely ought to be able to find some way to modify the present practice in order to make it possible for a deserving taxonomist to study the holotypes concerned in his work without forcing him to incur impossible burdens of expense and time which are now necessary. No changes in the policy of handling types should be made without due consideration of all the possible consequences, but there must be some way in which these difficulties could be overcome. Possibly some system of interinstitutional loans might be devised whereby the necessary type material could be concentrated at some institution near the worker concerned, and the latter be allowed to work there under proper supervision. There may be other possibilities in the way of solutions of this problem, but it is a serious enough one to challenge the best thought of all concerned. 
The practice of individual taxonomists in retaining types in their private collections is a distinct disadvantage to entomological taxonomy as a whole. In the first place it is an incentive to an individual for the mere describing of new species in order that he may gain the holotype for his own collection. If any incentives are allowed to exist in present-day matters to benefit entomological taxonomy as a whole, they should operate to discourage mere describing of new species, and encourage careful, monographic work. This the practice does not do. In the second place a holotype once designated and published, no longer rightfully belongs to the individual, but belongs to the whole entomological fraternity. This principle has been recognized with regard to the published description. The latter once published, belongs to entomological science and not to any individual. Any rights which the author may have had with regard to it are lost to him upon publication. This principle is much more true with regard to holotypes upon which descriptions are based. The holotypes are the standards with which other individuals of the same species may be compared. Standards, as such, belong to the entomological community as a whole and not to any individual. What nation would allow any individual for one moment to possess any standard of weight, measure, etc., as private property and exercise his rights of private property over it? Such standards are recognized as belonging to the community and are preserved by national governments as such.

The retention of holotypes in private collections then, should be discouraged, and individual workers should be encouraged, if not compelled to deposit holotypes in some one of the many existing institutional collections. Many of the petty disputes and personal enmities which have arisen, and will continue to arise, over the matter of access to holotypes in private collections would thereby be mostly eliminated. It is admitted that the original describer might occasionally have to visit the institution where his types were deposited, but this would be no greater hardship for him than for any other taxonomist working in the same field. All of the rights of the original describer would thereby be 
preserved, and the interest of the entomological community would be better served than at present.

\section{CONCLUSIONS}

1. A type specimen constitutes a standard by which other individuals of the same species may be measured and compared, and when so used it contributes accuracy and exactness to a field where doubt and confusion have been prevalent.

2. The argument that since early entomological workers did not use types, we should not, is not worthy of consideration by a scientific worker.

3. The establishment of the identity of species by means of type specimens is not opposed to the rules of nomenclature; on the contrary, the International Commission of Zoological Nomenclature has used this means of identifying species in rendering Opinion seventy-eight.

4. The principle that if a type is used to supplement a description and the conclusion reached thereby is contradictory to the description, then the use of the type is an abuse, is untenable, and would only lead to more confusion and more inaccuracies in taxonomic work.

5. Type specimens have come to be widely used and accepted in taxonomic work, because they add an element of certainty and exactness to such work, and not because certain taxonomists have a personal interest in maintaining the practice.

6. The use of type specimens has enabled taxonomists to achieve results of greater scientific value than the use of descriptions alone, and as long as types continue to contribute such a quality to taxonomic work, just so long will they be used, regardless of additional work or expense.

7. The best guarantee which a taxonomist can secure against injustices in the estimation of his work is a properly designated holotype for every species described, the holotype to be deposited in an institution where all may see. 
8. The comparison of type material by proxy does not tend to promote intellectual dishonesty among taxonomic workers. The exposing of concrete cases of dishonesty will do more to eliminate it than to abandon the use of type specimens.

9. With respect to honesty and reliability taxonomists as a group, will compare favorably with any other selected professional group, and the implication that type specimens in general are unreliable, due to the dishonesty of taxonomic workers, is entirely unjustifiable.

10. To eliminate type specimens and make the description everything, would be to substitute dogma for science, to substitute authority for research, an intolerable alternative.

11. Some method should be devised by which type specimens would be made more accessible to taxonomic workers than they are at present.

12. The practice of individual taxonomists in retaining types in their private collections is a distinct disadvantage to entomological taxonomy as a whole and should be discouraged.

\section{LITERATURE CITED}

Kleine, $R$. Die Typen der Familie Brenthidæ. Stettiner Ent. Zeit. 89:63-96. 1928.

Reitter, Edm. Über den eingebürgerten Missbrauch bei Benützung von entomologischen Typen. Wiener Ent. Zeit. 31 :21-26. 1912. 

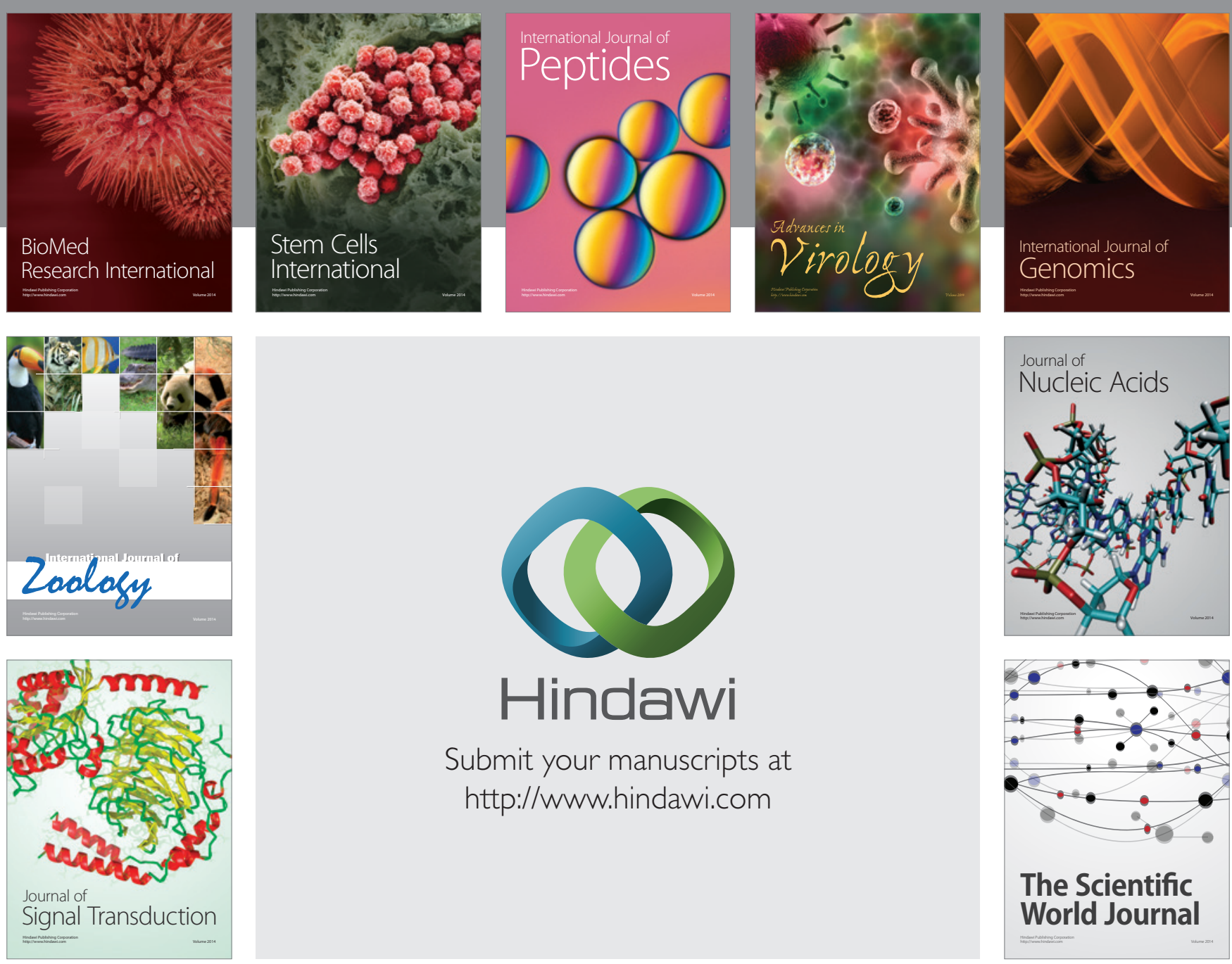

Submit your manuscripts at

http://www.hindawi.com
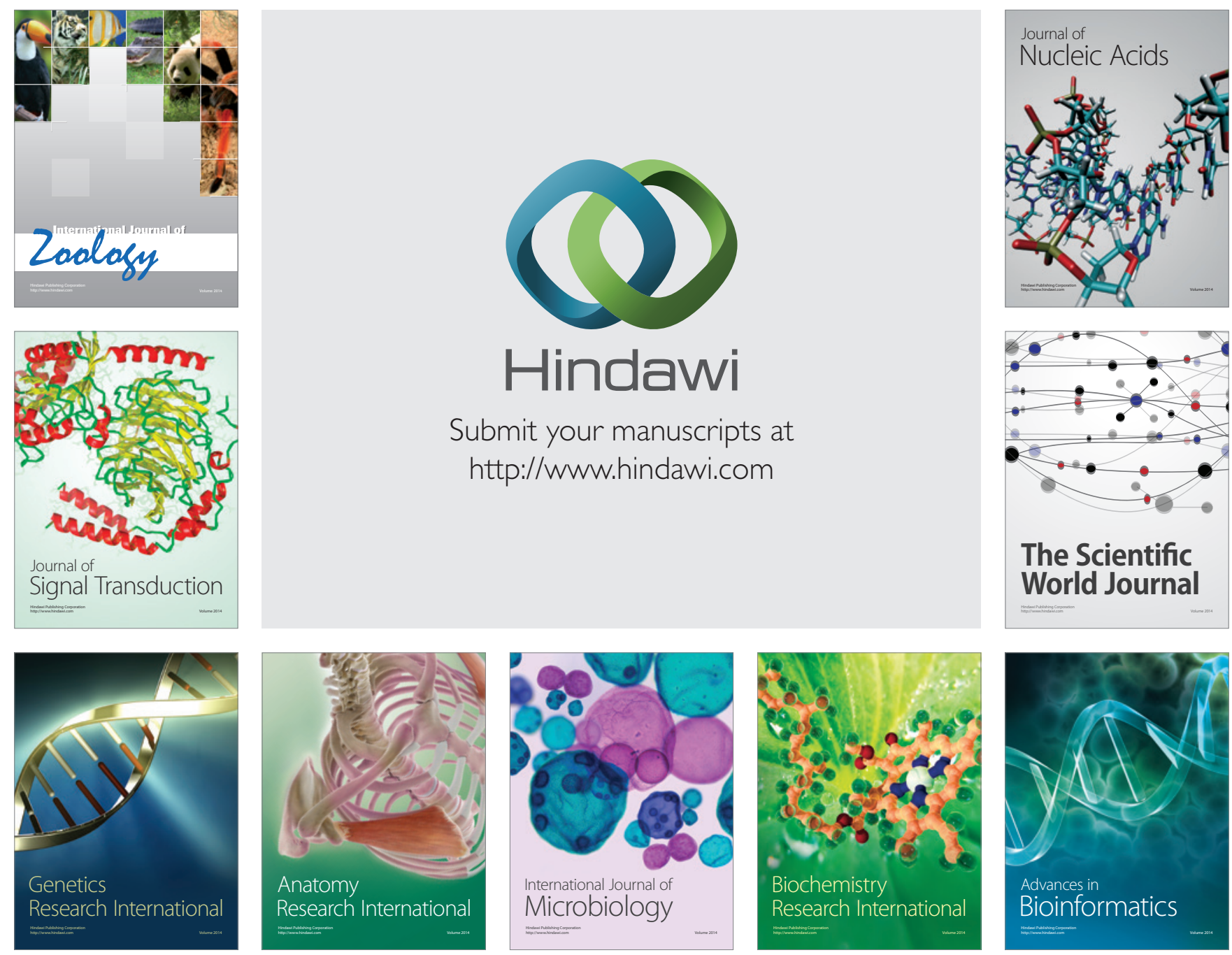

The Scientific World Journal
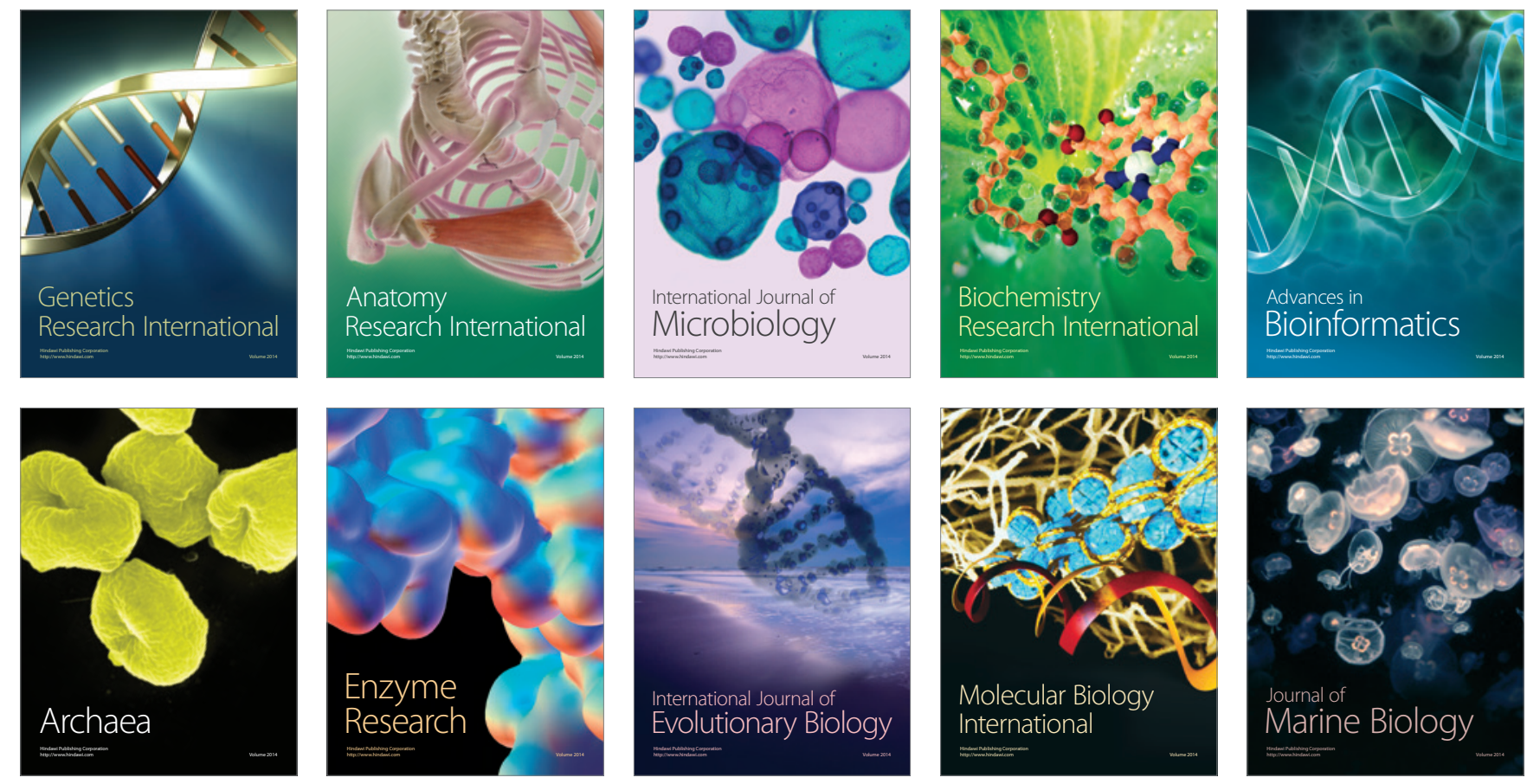